\title{
Variability in snow cover phenology in China from 1952 to 2010
}

\author{
Chang-Qing Ke ${ }^{1,2,6}$, Xiu-Cang $\mathrm{Li}^{3,4}$, Hongjie Xie ${ }^{5}$, Dong-Hui $\mathrm{Ma}^{1,6}$, Xun Liü ${ }^{1,2}$, and Cheng Kou ${ }^{1,2}$ \\ ${ }^{1}$ Jiangsu Provincial Key Laboratory of Geographic Information Science and Technology, Nanjing University, \\ Nanjing 210023, China \\ ${ }^{2}$ Key Laboratory for Satellite Mapping Technology and Applications of State Administration of Surveying, Mapping and \\ Geoinformation of China, Nanjing University, Nanjing 210023, China \\ ${ }^{3}$ National Climate Center, China Meteorological Administration, Beijing 100081, China \\ ${ }^{4}$ Collaborative Innovation Center on Forecast and Evaluation of Meteorological Disasters Faculty of Geography and Remote \\ Sensing, Nanjing University of Information Science \& Technology, Nanjing 210044, China \\ ${ }^{5}$ Department of Geological Sciences, University of Texas at San Antonio, Texas 78249, USA \\ ${ }^{6}$ Collaborative Innovation Center of South China Sea Studies, Nanjing 210023, China
}

Correspondence to: Chang-Qing Ke (kecq@nju.edu.cn)

Received: 12 February 2015 - Published in Hydrol. Earth Syst. Sci. Discuss.: 30 April 2015

Revised: 11 January 2016 - Accepted: 3 February 2016 - Published: 19 February 2016

\begin{abstract}
Daily snow observation data from 672 stations in China, particularly the 296 stations with over 10 mean snow cover days (SCDs) in a year during the period of 1952-2010, are used in this study. We first examine spatiotemporal variations and trends of SCDs, snow cover onset date (SCOD), and snow cover end date (SCED). We then investigate the relationships of SCDs with number of days with temperature below $0{ }^{\circ} \mathrm{C}$ (TBZD), mean air temperature (MAT), and Arctic Oscillation (AO) index. The results indicate that years with a positive anomaly of SCDs for the entire country include 1955, 1957, 1964, and 2010, and years with a negative anomaly of SCDs include 1953, 1965, 1999, 2002, and 2009. The reduced TBZD and increased MAT are the main reasons for the overall late SCOD and early SCED since 1952. This explains why only $12 \%$ of the stations show significant shortening of SCDs, while $75 \%$ of the stations show no significant change in the SCDs trends. Our analyses indicate that the distribution pattern and trends of SCDs in China are very complex and are not controlled by any single climate variable examined (i.e. TBZD, MAT, or AO), but a combination of multiple variables. It is found that the $\mathrm{AO}$ has the maximum impact on the shortening trends of SCDs in the Shandong peninsula, Changbai Mountains, Xiaoxingganling, and north Xinjiang, while the combined TBZD and MAT have the maximum impact on the shortening trends of SCDs in the Loess Plateau, Tibetan Plateau, and Northeast Plain.
\end{abstract}

\section{Introduction}

Snow has a profound impact on the surficial and atmospheric thermal conditions, and is very sensitive to climatic and environmental changes, because of its high reflectivity, low thermal conductivity, and hydrological effects via snowmelt (Barnett et al., 1989; Groisman et al., 1994). The extent of snow cover in the Northern Hemisphere has decreased significantly over the past decades because of global warming (Robinson and Dewey, 1990; Brown and Robinson, 2011). Snow cover showed the largest decrease in the spring, and the decrease rate increased for higher latitudes in response to larger albedo feedback (Déry and Brown, 2007). In North America, snow depth in central Canada showed the greatest decrease (Dyer and Mote, 2006), and snowpack in the Rocky Mountains in the United States declined (Pederson et al., 2013). However, in situ data showed a significant increase in snow accumulation in winter but a shorter snowmelt season over Eurasia (Bulygina et al., 2009). Decrease in snowpack has also been found in the European Alps in the last 20 years of the twentieth century (Scherrer et al., 2004), but a very long time series of snowpack suggests large decadal variability and overall weak long-term trends only (Scherrer et al., 2013). Meteorological data indicated that the snow cover over northwest China exhibited a weak upward trend in snow depth (Qin et al., 2006), with large spatiotemporal variations (Ke et al., 2009; Ma and Qin, 2012). Simulation exper- 
iments using climate models indicated that, with continuing global warming, the snow cover in China would show more variations in space and time than ever before (Shi et al., 2011; Ji and Kang, 2013). Spatiotemporal variations of snow cover are also manifested as snowstorms or blizzards, particularly excessive snowfall over a short time duration (Bolsenga and Norton, 1992; Liang et al., 2008; Gao, 2009; Wang et al., 2013; Llasat et al., 2014).

Total snow cover days in a year (SCDs hereafter) is an important index that represents the environmental features of climate (Ye and Ellison, 2003; Scherrer et al., 2004), and is directly related to the radiation and heat balance of the Earthatmosphere system. The SCDs vary in space and time and contribute to climate change over short timescales (Zhang, 2005), especially in the Northern Hemisphere. Bulygina et al. (2009) investigated the linear trends of SCDs observed at 820 stations from 1966 to 2007, and indicated that the duration of snow cover decreased in the northern regions of European Russia and in the mountainous regions of southern Siberia, while it increased in Yakutia and the Far East. Peng et al. (2013) analysed trends in the snow cover onset date (SCOD) and snow cover end date (SCED) in relation to temperature over the past 27 years (1980-2006) from over 636 meteorological stations in the Northern Hemisphere. They found that the SCED remained stable over North America, whereas there was an early SCED over Eurasia. Satellitederived snow data indicated that the average snow season duration over the Northern Hemisphere decreased at a rate of 5.3 days per decade between 1972/1973 and 2007/2008 (Choi et al., 2010). Their results also showed that a major change in the trend of snow duration occurred in the late 1980s, especially in western Europe, central and East Asia, and mountainous regions in western United States.

There are large spatiotemporal differences in the SCDs in China (Wang and $\mathrm{Li}, 2012$ ). Analysis of 40 meteorological stations from 1971 to 2010 indicated that the SCDs had a significant decreasing trend in the western and south-eastern Tibetan Plateau, with the largest decline observed in Nielamu, reaching 9.2 days per decade (Tang et al., 2012). Data analysis also indicated that the SCDs had a linear decreasing trend at most stations in the Hetao region and its vicinity (Xi et al., 2009). However, analysis of meteorological station data in Xinjiang showed that the SCDs had a slight increasing trend, occurring mainly in 1960-1980 (Q. Wang et al., 2009). Li et al. (2009) analysed meteorological data from 80 stations in Heilongjiang province, Northeast China. Their results showed that the snow cover duration shortened, because of both the late SCOD (by 1.9 days per decade) and early SCED (by 1.6 days per decade), which took place mainly in the lower altitude plains.

The SCDs are sensitive to local winter temperature and precipitation, latitude (Hantel et al., 2000; C. Wang et al., 2009; Serquet et al., 2011; Morán-Tejeda et al., 2013), and altitudinal gradient and terrain roughness (Lehning et al., 2011; Ke and Liu, 2014). Essentially, the variation in SCDs is mainly attributed to large-scale atmospheric circulation or climatic forcing (Beniston, 1997; Scherrer and Appenzeller, 2006; Ma and Qin, 2012; Birsan and Dumitrescu, 2014), such as monsoons, the El Niño-Southern Oscillation, the North Atlantic Oscillation, and the Arctic Oscillation (AO). Xu et al. (2010) investigated the relationship between the SCDs and monsoon index in the Tibetan Plateau and their results indicated that there were great spatial differences. As an index of the dominant pattern of non-seasonal sea-level pressure variations, the $\mathrm{AO}$ shows a large impact on the winter weather patterns of the Northern Hemisphere (Thompson and Wallace, 1998; Thompson et al., 2000; Gong et al., 2001; Wu and Wang, 2002; Jeong and Ho, 2005). The interannual variation of winter extreme cold days in the northern part of eastern China is closely linked to the AO (Chen et al., 2013). Certainly, the AO plays an important role in the variation of SCDs. An increase in the SCDs before 1990 and a decrease after 1990 have been reported in the Tibetan Plateau, and snow duration has positive correlations with the winter AO index (You et al., 2011), and a significant correlation between the AO and snowfall over the Tibetan Plateau on an inter-decadal timescale was also reported by Lü et al. (2008).

The focus of this study is the variability in the snow cover phenology in China. A longer time series of daily observations of snow cover is used for these spatial and temporal analyses. We first characterise the spatial patterns of change in the SCDs, SCOD, and SCED in different regions of China; we then examine the sensitivity of SCDs to the number of days with temperature below $0{ }^{\circ} \mathrm{C}$ (TBZD), the mean air temperature (MAT), and the Arctic Oscillation (AO) index during the snow season (between SCOD and SCED).

\section{Data and methods}

\subsection{Data}

We use daily snow cover and temperature data in China from the 1 September 1951 to the 31 August 2010, provided by the National Meteorological Information Centre of China Meteorological Administration (CMA). According to the Specifications for Surface Meteorological Observations (China Meteorological Administration, 2003), an SCD is defined as a day when the snow cover in the area meets the following requirement: at least half of the observation field is covered by snow. For any day with at least half of the observation field covered by snow, snow depth is recorded as a rounded-up integer. For example, a normal SCD is recorded if the snow depth is equal to or more than $1.0 \mathrm{~cm}$ (measured with a ruler), or a thin SCD if the snow depth is less than $1.0 \mathrm{~cm}$. A snow year is defined as the time period from 1 September of the previous year to 31 August of the current year. For instance, September, October, and November 2009 are treated as the autumn season of snow year 2010, December 2009 and January and February 2010 as the winter season of snow year 


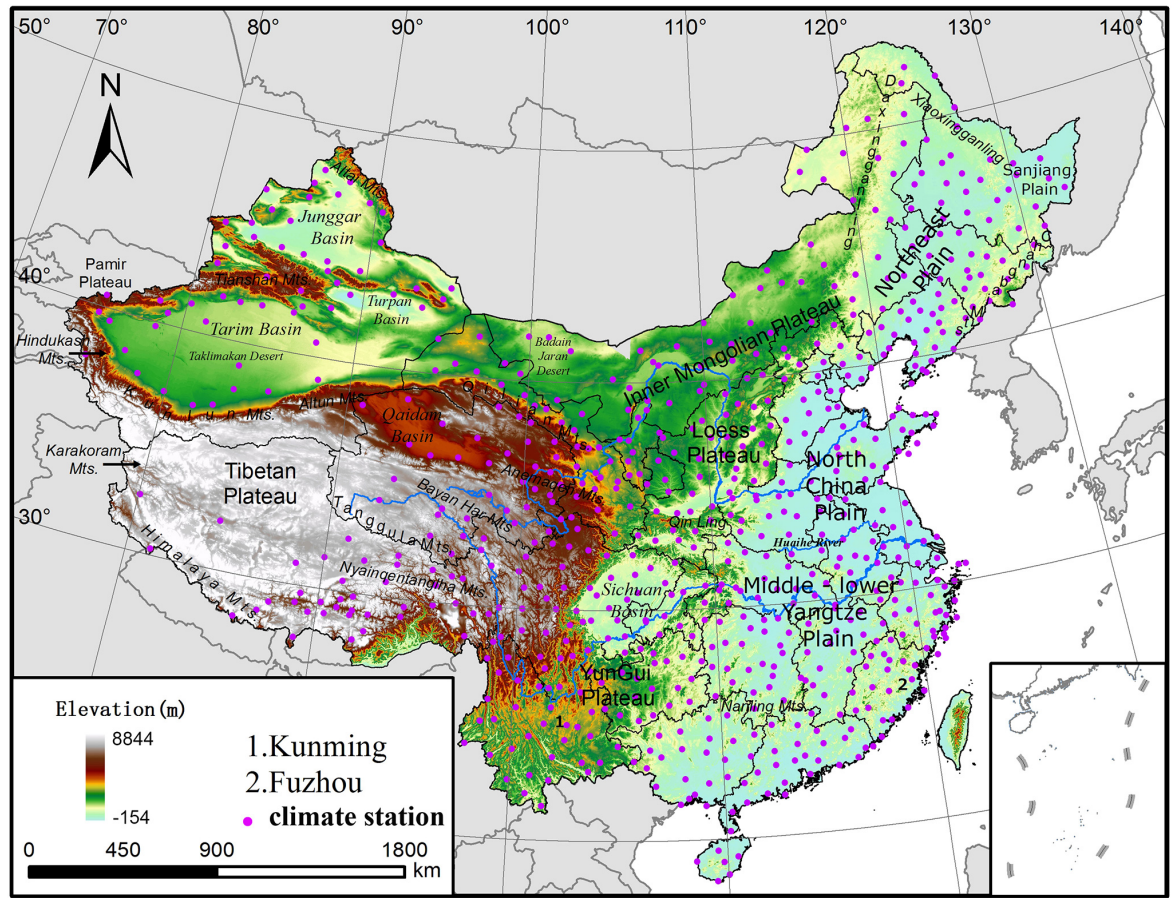

Figure 1. Locations of weather stations and major basins, mountains, and plains mentioned in the paper, overlying the digital elevation model for China.

2010, and March, April, and May 2010 as the spring season of snow year 2010.

Station density is high in eastern China, where the observational data for most stations are complete, with relatively long histories (as long as 59 years), while station density is low in western China, and the observation history is relatively short, although two of the three major snow regions are located in western China. If all stations with short time series are eliminated, the spatial representativeness of the data set would be a problem. Therefore, a time series of at least 30 years is included in this study.

Because of topography and climate conditions, the discontinuous nature of snowfall is obvious in western China, especially in the Tibetan Plateau, with patchy snow cover, and there are many thin SCD records (Ke and $\mathrm{Li}, 1998)$. However, in order to enhance data reliability, according to the previous studies (An et al., 2009; Wang and $\mathrm{Li}, 2012$ ), thin SCDs in the original data set are not taken into account in this paper.

Totally, there are 722 stations in the original data set. Since station relocation and changes in the ambient environment could cause inconsistencies in the recorded data, we implement strict quality controls (such as inspection for logic, consistency, and uniformity) on the observational data sets in order to reduce errors (Ren et al., 2005). The standard normal homogeneity test (Alexandersson and Moberg, 1997) at the $95 \%$ confidence level is applied to the SCDs and temperature series data in order to identify possible breakpoints.
Time series gap filling is performed after all inhomogeneities are eliminated, using nearest neighbour interpolation. After being processed as mentioned above, the 672 stations with annual mean SCDs greater than 1 (day) are finally selected for subsequent investigation (Fig. 1).

The observation period for each station is different, varying between 59 years (1951/1952-2009/2010) and 30 years (1980/1981-2009/2010). Overall, 588 stations have observation records between 50 and 59 years, 47 stations between 40 and 49 years, and 37 stations between 30 and 39 years (Fig. 2). Most of the stations with observation records of less than 50 years are located in remote or high-elevation areas. All 672 stations are used to analyse the spatiotemporal distribution of SCDs in China, while only 296 stations with more than 10 annual mean SCDs are used to study the changes of the relationships of SCOD, SCED, and SCDs with TBZD, MAT, and the AO index.

The daily AO index constructed by projecting the daily (00Z) $1000 \mathrm{mb}$ height anomalies poleward of $20^{\circ} \mathrm{N}$, from http://www.cpc.ncep.noaa.gov/products/precip/ CWlink/daily_ao_index/ao.shtml, is used. A positive (negative) AO index corresponds to low (high) pressure anomalies throughout the polar region and high (low) pressure anomalies across the subtropical and midlatitudes (Peings et al., 2013). We average the daily AO indexes during the snow season of each station as the $\mathrm{AO}$ index of the snow year. A time series of AO indexes from 1952 to 2010, for each of the 296 stations, is then constructed. 


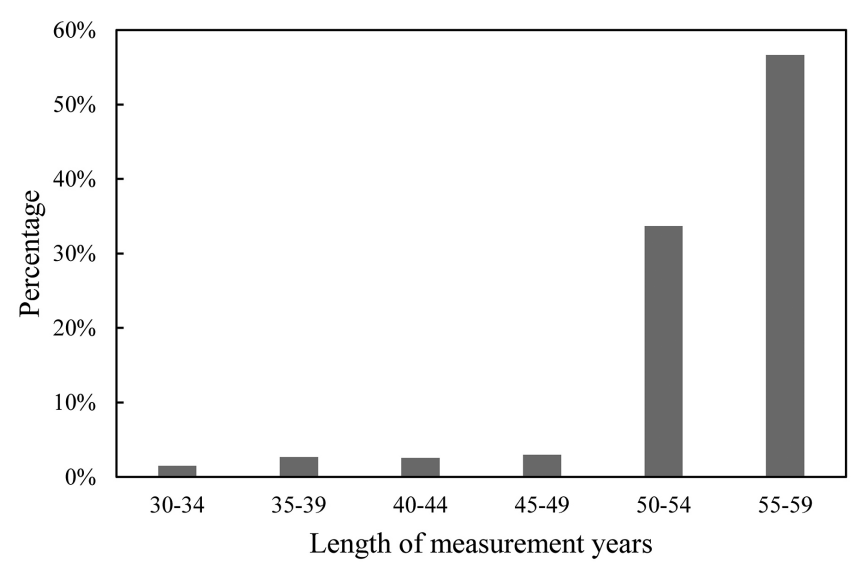

Figure 2. Percentage of weather stations with different measurement lengths.

A digital elevation model from the Shuttle Radar Topographic Mission (SRTM, http://srtm.csi.cgiar.org) of the National Aeronautics and Space Administration (NASA) with a resolution of $90 \mathrm{~m}$ and the administration map of China are used as the base map.

\subsection{Methods}

We apply a Mann-Kendall (MK) test to analyse the trends of SCDs, SCOD, and SCED. The MK test is an effective tool to extract the trends of time series, and is widely applied to the analysis of climate series (Marty, 2008). The MK test is characterised as being more objective, since it is a non-parametric test. A positive standardised MK statistic value indicates an upward or increasing trend, while a negative value demonstrates a downward or decreasing trend. Confidence levels of 90 and $95 \%$ are taken as thresholds to classify the significance of positive and negative trends of SCDs, SCOD, and SCED.

At the same time, if SCDs, SCOD, or SCED at one climate station has a significant MK trend (above $90 \%$ ), their linear regression analyses are performed against time, respectively. The slopes of the regressions represent the changing trends and are expressed in days per decade. The statistical significance of the slope for each of the linear regressions is assessed by the Student's $t$ test (two-tailed test of the Student $t$ distribution), and confidence levels of 90 and $95 \%$ are considered.

Correlation analysis is used to examine the SCDs relationships with the TBZD, MAT, and the AO index, and the Pearson product-moment correlation coefficients (PPMCCs) have been calculated. The PPMCC is a widely used estimator for describing the spatial dependence of rainfall processes, and it indicates the strength of the linear covariance between two variables (Habib et al., 2001; Ciach and Krajewski, 2006). The statistical significance of the correlation coefficients is calculated using the Student's $t$ test, and confidence levels above $90 \%$ are considered significant in our analysis.

The spatial distribution of SCDs, SCOD, and SCED, and their calculated results, are spatially interpolated by applying the ordinary Kriging method.

\section{Results}

\subsection{Cross-validation of the spatial interpolations}

All mean errors are near zero, all average standard errors are close to the corresponding root mean squared errors, and all root mean squared standardised errors are close to 1 (Table 1). Prediction errors are unbiased and valid, except for slightly overestimated coefficients of variation (CVs) and slightly underestimated SCDs in 2002. Overall, the interpolation results have small errors and are acceptable.

\subsection{Spatiotemporal variations of SCDs}

\subsubsection{Spatial distribution of SCDs}

The analysis of observations from 672 stations indicates that there are three major stable snow regions with more than 60 annual mean SCDs (Li, 1990): Northeast China, north Xinjiang, and the Tibetan Plateau, with Northeast China being the largest of the three (Fig. 3a). In the Daxinganling, Xiaoxingganling, and Changbai Mountains of Northeast China, there are more than 90 annual mean SCDs, corresponding to a relatively long snow season. The longest annual mean SCDs, 163 days, is at Arxan Station (in the Daxinganling Mountains) in Inner Mongolia. In north Xinjiang, the SCDs are relatively long in the Tianshan and Altun Mountains, followed by the Junggar Basin. The annual mean SCDs in the Himalayas, Nyainqentanglha, Tanggula Mountains, Bayan Har Mountains, Anemaqen Mountains, and Qilian Mountains of the Tibetan Plateau are relatively long, although most of these regions have fewer than 60 annual SCDs. The Tibetan Plateau has a high elevation, a cold climate, and many glaciers, but its mean SCDs are not as large as those of the other two stable snow regions.

Areas with SCDs of 10-60 per year are called unstable snow regions with annual periodicity (definite snow cover every winter) ( $\mathrm{Li}, 1990)$. It includes the peripheral parts of the three major stable snow regions, Loess Plateau, Northeast Plain, North China Plain, Shandong peninsula, and regions north of the Qinling-Huaihe line (along the Qinling Mountains and Huaihe River to the east). Areas with SCDs of 1-10 per year are called unstable snow regions without annual periodicity (the mountainous regions are excluded) ( $\mathrm{Li}$, 1990). It includes the Qaidam Basin, the Badain Jaran desert, the peripheral parts of Sichuan Basin, the northeast part of the Yungui Plateau, and the middle and lower Yangtze River Plain. Areas with occasional snow and mean annual SCDs of less than 1.0 (day) are distributed north of the Sichuan 
Table 1. Prediction errors of cross-validation for the spatial interpolation with the ordinary Kriging method (the unit is day for snow cover days (SCDs), snow cover onset day (SCOD), and snow cover end day (SCED); there is no unit for the coefficient of variation (CV)).

\begin{tabular}{lllll}
\hline $\begin{array}{l}\text { Item } \\
\text { (figures) }\end{array}$ & $\begin{array}{l}\text { Mean } \\
\text { error }\end{array}$ & $\begin{array}{l}\text { Average standard } \\
\text { error }\end{array}$ & $\begin{array}{l}\text { Root mean } \\
\text { squared error }\end{array}$ & $\begin{array}{l}\text { Root mean squared } \\
\text { standardised error }\end{array}$ \\
\hline Mean SCD (Fig. 3a) & -0.0230 & 11.0558 & 13.7311 & 1.1097 \\
CV (Fig. 3b) & 0.0017 & 0.7364 & 0.5510 & 0.7579 \\
SCD $_{\text {in 1957 (Fig. 5a) }}$ & -0.0015 & 11.1561 & 13.4662 & 1.1898 \\
SCD in 2002 (Fig. 5b) & 0.0306 & 6.6185 & 8.5887 & 1.2522 \\
SCD in 2008 (Fig. 5c) & 0.0477 & 7.3167 & 8.1968 & 1.0969 \\
SCED in 1957 (Fig. 5d) & -0.0449 & 15.0528 & 18.9860 & 1.1921 \\
SCED in 1997 (Fig. 5e) & 0.0696 & 15.5722 & 17.7793 & 1.1040 \\
SCOD in 2006 (Fig. 5f) & 0.0482 & 15.4503 & 16.1757 & 1.0449 \\
SCOD (Fig. 8a) & 0.0293 & 11.2458 & 13.9078 & 1.1712 \\
SCED (Fig. 8b) & -0.0222 & 15.2265 & 18.3095 & 1.1308 \\
\hline
\end{tabular}
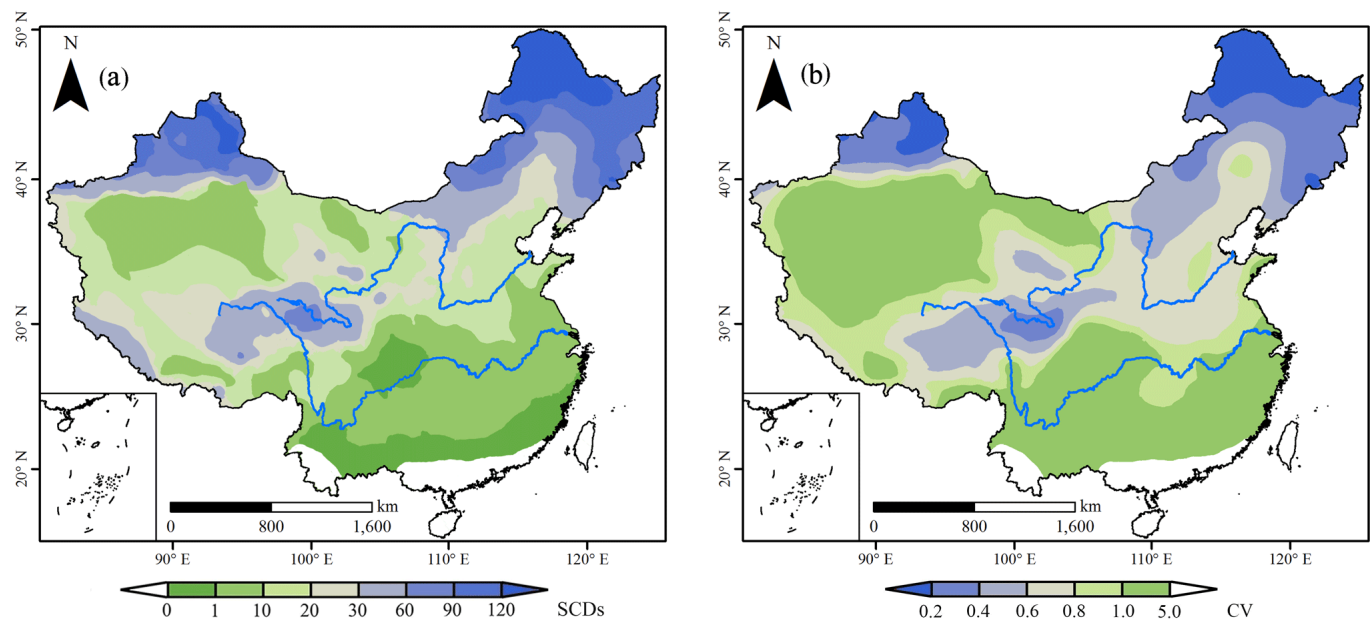

Figure 3. Annual mean snow cover days (SCDs) from 1980/1981 to 2009/2010 (a), and their coefficients of variation (CVs) (b).

Basin and in the belt along Kunming, Nanling Mountains, and Fuzhou (approximate latitude of $25^{\circ} \mathrm{N}$ ). Because of the latitude or local climate and terrain, there is no snow in the Taklimakan Desert, Turpan Basin, the Yangtze River Valley in the Sichuan Basin, the southern parts of Yunnan, Guangxi, Guangdong, and Fujian, and on the island of Hainan.

The spatial distribution pattern of SCDs based on climate data with longer time series is similar to previous studies (Li and Mi, 1983; Li, 1990; Liu et al., 2012; C. Wang et al., 2009; Wang and Li, 2012). Snow distribution is closely linked to latitude and elevation, and is generally consistent with the climate zones (Lehning et al., 2011; Ke and Liu, 2014). There are relatively more SCDs in Northeast China and north Xinjiang, and fewer SCDs to the south (Fig. 3a). In the Tibetan Plateau, located in south-western China, the elevation is higher than eastern areas at the same latitude, and the SCDs are greater than in eastern China (Tang et al., 2012). The amount of precipitation also plays a critical role in determining the SCDs (Hantel et al., 2000). In the northeastern coastal areas of China, which are affected consider- ably by the ocean, there is much precipitation. In north Xinjiang, which has a typical continental (inland) climate, the precipitation is less than in Northeast China, and there are more SCDs in the north of Northeast China than in north Xinjiang (Dong et al., 2004; Q. Wang et al., 2009). Moreover, the local topography has a relatively large impact on the SCDs (Lehning et al., 2011). The Tarim Basin is located inland, with relatively little precipitation, thus snowfall there is extremely rare except in the surrounding mountains $(\mathrm{Li}$, 1993). The Sichuan Basin is surrounded by high mountains, therefore situated in the precipitation shadow in winter, resulting in fewer SCDs (Li and Mi, 1983; Li, 1990).

The three major stable snow regions, Northeast China, north Xinjiang, and the eastern Tibetan Plateau, have smaller CVs in the SCDs (Fig. 3b). Nevertheless, the SCDs in arid or semi-arid regions, such as South Xinjiang, the northern and south-western Tibetan Plateau, and central and western Inner Mongolia, show large fluctuations because there is little precipitation during the cold seasons, and certainly little snowfall and large CVs of SCDs. In particular, the Taklimakan 


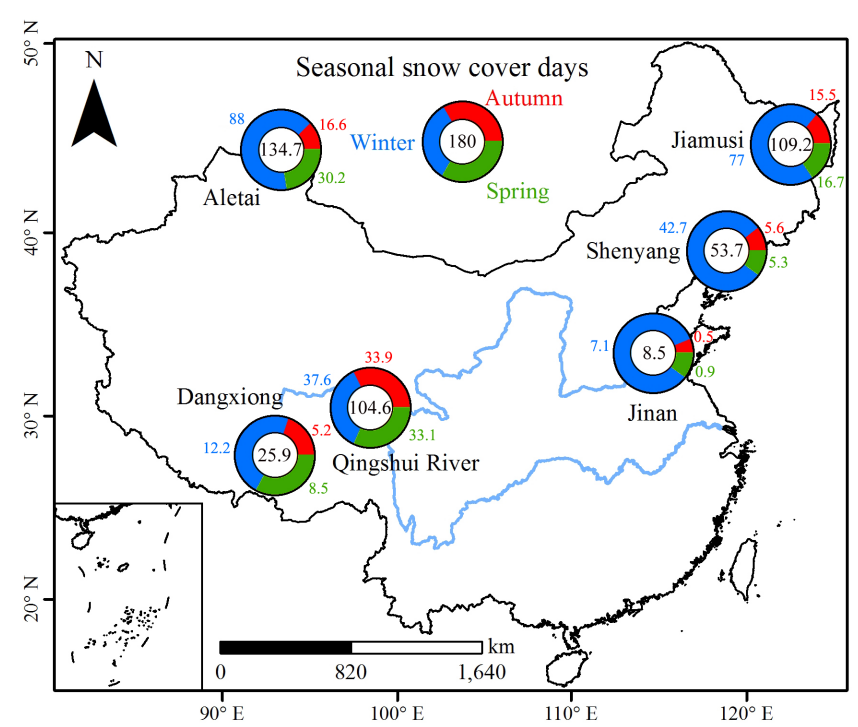

Figure 4. Seasonal variation of SCDs; the number in the centre denotes annual mean SCDs, the blue colour in the circle the SCDs represents the winter season, the green colour spring, and the red colour autumn.

Desert in the Tarim Basin is an extremely arid region, with only occasional snowfall. Therefore, it has a very large range of fluctuations of SCDs. Additionally, the middle and lower Yangtze River Plain also has large SCDs fluctuations because of warm-temperate or subtropic climate with a short winter and little snowfall. Generally, the fewer the SCDs, the larger the CV (C. Wang et al., 2009). This is consistent with other climate variables, such as precipitation (Yang et al., 2015).

\subsubsection{Temporal variations of SCDs}

Seasonal variation of SCDs is primarily controlled by temperature and precipitation (Hantel et al., 2000; Scherrer et al., 2004; Liu et al., 2012). In north Xinjiang and Northeast China, snow is primarily concentrated in the winter (Fig. 4). In these regions, the SCDs exhibit a singlepeak distribution. In the Tibetan Plateau, however, the seasonal variation of SCDs is slightly different, i.e. more snow in the spring and autumn combined than in the winter. The mean temperature and precipitation at Dangxiong station $\left(30^{\circ} 29^{\prime} \mathrm{N}, 91^{\circ} 06^{\prime} \mathrm{E} ; 4200.0 \mathrm{~m}\right)$ in winter are $-7.7^{\circ} \mathrm{C}$ and $7.9 \mathrm{~mm}$, respectively, and those at Qingshuihe station $\left(33^{\circ} 48^{\prime} \mathrm{N}, 97^{\circ} 08^{\prime} \mathrm{E} ; 4415.4 \mathrm{~m}\right)$ are $-15.8^{\circ} \mathrm{C}$ and $16.3 \mathrm{~mm}$, respectively. It is too cold and dry to produce enough snow in the Tibetan Plateau (Hu and Liang, 2014).

The temporal variation of SCDs shows very large differences from 1 year to another. We define a year with a positive (negative) anomaly of SCDs in the following way: for a given year, if $70 \%$ of the stations have a positive (negative) anomaly and $30 \%$ of the stations have SCDs larger (smaller) than the mean \pm 1 standard deviation ( $1 \mathrm{SD}$ ), it is regarded as a year with a positive (negative) anomaly of SCDs. The years with a positive anomaly of SCDs in China are 1955, 1957, 1964, and 2010 (Table 2). Moreover, the stations with SCDs larger than the mean +2 SD account for 25 and $26 \%$ of all stations in 1955 and 1957, respectively, and these 2 years are considered as years with an extremely positive anomaly of SCDs. In 1957, there was an almost nationwide positive anomaly of SCDs except for north Xinjiang (Fig. 5a). This 1957 event had a great impact on agriculture, natural ecology, and social-economic systems, and resulted in a heavy snow-caused disaster (Hao et al., 2002).

Years with a negative anomaly of SCDs include 1953, 1965, 1999, 2002, and 2009 (Table 2). If there is too little snowfall in a specific year, a drought is possible. Drought resulting from little snowfall in the cold season is a slow process and can sometimes cause serious damages. For example, East China displayed an apparent negative anomaly of SCDs in 2002 (Fig. 5b), and had very little snowfall, leading to an extreme winter drought in Northeast China, where snowfall is the primary form of winter precipitation (Fang et al., 2014).

Because of different atmospheric circulation backgrounds, vapour sources, and topographic conditions in different regions of China, there are great differences in the SCDs, even in 1 year. For example, in 2008, there were more SCDs and longer snow duration in the Yangtze River Basin, North China, and the Tianshan Mountains in Xinjiang (Fig. 5c), especially in the Yangtze River Basin, where large snowfall was normally not observed. However, four episodes of severe and persistent snow, extreme low temperatures, and freezing weather occurred in 2008 and led to a large-scale snowstorm in this region (Gao, 2009). As reported by the Ministry of Civil Affairs of China, the 2008 snowstorm killed 107 people and caused losses of USD 15.45 billion. Both the SCDs and scale of economic damage broke records from the past 5 decades (Wang et al., 2008). On the contrary, there was no snowstorm in north Xinjiang, the Tibetan Plateau, and PanBohai Bay region in 2008. Moreover, Northeast China had an apparent negative anomaly of SCDs (Fig. 5c).

There are great differences in the temporal variations of $\mathrm{SCDs}$, even in the three major stable snow regions. If we redefine a year with a positive (negative) anomaly of SCDs using a much higher standard (i.e. $80 \%$ of stations have a positive (negative) anomaly and $40 \%$ of stations have an SCDs larger (smaller) than the mean $\pm 1 \mathrm{SD}$ ), it is found that 1957, 1973, and 2010 are years with a positive anomaly of SCDs in Northeast China, while 1959, 1963, 1967, 1998, 2002, and 2008 are years with a negative anomaly of SCDs (Table 3, Fig. 5a-c). Years with a positive anomaly of SCDs in north Xinjiang include 1960, 1977, 1980, 1988, 1994, and 2010, and years with a negative anomaly of SCDs include 1974, 1995, and 2008 (Table 3, Fig. 5c). North Xinjiang is one of the regions prone to extreme snow events, where frequent heavy snowfall greatly affects the development of animal husbandry (Hao et al., 2002). 
Table 2. Percentage (\%) of stations with anomalies (P for positive and $\mathrm{N}$ for negative) of snow cover days (SCDs) in a year, snow cover onset date (SCOD), and snow cover end date (SCED). Percentage (\%) of stations with anomalies of SCDs, SCOD, and SCED larger (smaller) than the mean \pm 1 or 2 standard deviations (SD), with the bold number denoting years with a positive (negative) anomaly of SCDs, and late (early) years for SCOD or SCED in China. All the percentages are calculated based on 672 stations.

\begin{tabular}{|c|c|c|c|c|c|c|c|c|c|c|c|c|c|c|c|c|c|c|}
\hline \multirow[b]{2}{*}{ Year } & \multicolumn{6}{|c|}{ SCDs } & \multicolumn{6}{|c|}{ SCOD } & \multicolumn{6}{|c|}{ SCED } \\
\hline & $\mathrm{P}$ & $1 \mathrm{SD}$ & $2 \mathrm{SD}$ & $-2 \mathrm{SD}$ & $-1 \mathrm{SD}$ & $\mathrm{N}$ & $\mathrm{P}$ & $1 \mathrm{SD}$ & $2 \mathrm{SD}$ & $-2 \mathrm{SD}$ & $-1 \mathrm{SD}$ & $\mathrm{N}$ & $\mathrm{P}$ & $1 \mathrm{SD}$ & $2 \mathrm{SD}$ & $-2 \mathrm{SD}$ & $-1 \mathrm{SD}$ & $\mathrm{N}$ \\
\hline 1952 & 31 & 2 & 0 & 13 & 33 & 69 & 69 & 40 & 21 & 2 & 9 & 31 & 55 & 17 & 2 & 12 & 17 & 45 \\
\hline 1953 & 28 & 7 & 0 & 3 & 36 & 72 & 40 & 8 & 2 & 2 & 18 & 60 & 37 & 8 & 1 & 10 & 18 & 63 \\
\hline 1954 & 57 & 31 & 12 & 0 & 8 & 43 & 35 & 8 & 4 & 1 & 18 & 65 & 56 & 11 & 0 & 0 & 10 & 44 \\
\hline 1955 & 79 & 45 & 25 & 1 & 5 & 21 & 37 & 9 & 4 & 1 & 22 & 63 & 77 & 21 & 2 & 1 & 6 & 23 \\
\hline 1956 & 46 & 10 & 0 & 0 & 4 & 54 & 69 & 20 & 2 & 0 & 9 & 31 & 61 & 24 & 1 & 2 & 12 & 39 \\
\hline 1957 & 85 & 62 & 26 & 0 & 3 & 15 & 26 & 6 & 1 & 0 & 15 & 74 & 84 & 35 & 5 & 1 & 4 & 16 \\
\hline 1958 & 48 & 15 & 4 & 0 & 14 & 52 & 46 & 17 & 0 & 0 & 18 & 54 & 52 & 17 & 3 & 4 & 18 & 48 \\
\hline 1959 & 28 & 7 & 1 & 4 & 23 & 72 & 53 & 26 & 8 & 1 & 18 & 47 & 59 & 23 & 3 & 1 & 5 & 41 \\
\hline 1960 & 37 & 13 & 3 & 0 & 16 & 63 & 49 & 11 & 2 & 0 & 10 & 51 & 59 & 24 & 6 & 4 & 18 & 41 \\
\hline 1961 & 36 & 7 & 1 & 1 & 18 & 64 & 25 & 9 & 2 & 1 & 27 & 75 & 30 & 6 & 1 & 7 & 26 & 70 \\
\hline 1962 & 41 & 11 & 3 & 0 & 10 & 59 & 44 & 13 & 4 & 2 & 10 & 56 & 58 & 18 & 3 & 0 & 11 & 42 \\
\hline 1963 & 25 & 5 & 2 & 2 & 27 & 75 & 34 & 14 & 5 & 1 & 23 & 66 & 51 & 14 & 0 & 8 & 17 & 49 \\
\hline 1964 & 76 & 36 & 11 & 0 & 1 & 24 & 31 & 3 & 1 & 4 & 24 & 69 & 64 & 18 & 1 & 0 & 5 & 36 \\
\hline 1965 & 26 & 8 & 0 & 1 & 32 & 74 & 59 & 18 & 5 & 1 & 8 & 41 & 55 & 14 & 2 & 3 & 17 & 45 \\
\hline 1966 & 28 & 6 & 1 & 0 & 13 & 72 & 46 & 21 & 6 & 0 & 13 & 54 & 67 & 12 & 1 & 2 & 5 & 33 \\
\hline 1967 & 31 & 5 & 0 & 3 & 23 & 69 & 40 & 11 & 3 & 2 & 15 & 60 & 43 & 5 & 0 & 3 & 12 & 57 \\
\hline 1968 & 61 & 29 & 12 & 3 & 8 & 39 & 35 & 8 & 1 & 0 & 13 & 65 & 34 & 13 & 0 & 4 & 26 & 66 \\
\hline 1969 & 42 & 18 & 5 & 4 & 21 & 58 & 45 & 13 & 1 & 3 & 20 & 55 & 67 & 20 & 1 & 1 & 7 & 33 \\
\hline 1970 & 46 & 15 & 1 & 2 & 11 & 54 & 38 & 10 & 3 & 2 & 24 & 62 & 62 & 19 & 3 & 0 & 7 & 38 \\
\hline 1971 & 53 & 12 & 1 & 1 & 9 & 47 & 38 & 15 & 4 & 1 & 17 & 62 & 53 & 9 & 1 & 1 & 8 & 47 \\
\hline 1972 & 55 & 23 & 11 & 0 & 8 & 45 & 37 & 9 & 2 & 1 & 21 & 63 & 46 & 16 & 4 & 1 & 9 & 54 \\
\hline 1973 & 50 & 19 & 2 & 1 & 7 & 50 & 35 & 10 & 1 & 2 & 23 & 65 & 43 & 9 & 1 & 1 & 8 & 57 \\
\hline 1974 & 33 & 8 & 0 & 3 & 23 & 67 & 53 & 29 & 6 & 1 & 11 & 47 & 52 & 12 & 1 & 1 & 10 & 48 \\
\hline 1975 & 41 & 10 & 4 & 1 & 15 & 59 & 26 & 7 & 2 & 1 & 21 & 74 & 43 & 15 & 3 & 2 & 16 & 57 \\
\hline 1976 & 35 & 11 & 3 & 1 & 23 & 65 & 60 & 25 & 12 & 0 & 5 & 40 & 77 & 31 & 5 & 1 & 3 & 23 \\
\hline 1977 & 45 & 20 & 3 & 0 & 9 & 55 & 28 & 5 & 1 & 0 & 25 & 72 & 57 & 14 & 3 & 2 & 12 & 43 \\
\hline 1978 & 60 & 22 & 8 & 0 & 2 & 40 & 43 & 13 & 2 & 2 & 13 & 57 & 55 & 10 & 1 & 0 & 8 & 45 \\
\hline 1979 & 41 & 8 & 1 & 0 & 7 & 59 & 43 & 11 & 1 & 0 & 20 & 57 & 79 & 32 & 2 & 0 & 4 & 21 \\
\hline 1980 & 39 & 12 & 1 & 0 & 5 & 61 & 41 & 9 & 1 & 1 & 16 & 59 & 82 & 27 & 2 & 0 & 4 & 18 \\
\hline 1981 & 42 & 13 & 2 & 0 & 13 & 58 & 45 & 20 & 4 & 2 & 18 & 55 & 44 & 13 & 1 & 2 & 15 & 56 \\
\hline 1982 & 40 & 12 & 1 & 1 & 15 & 60 & 23 & 9 & 2 & 0 & 30 & 77 & 58 & 23 & 6 & 6 & 16 & 42 \\
\hline 1983 & 50 & 19 & 6 & 0 & 12 & 50 & 44 & 14 & 1 & 1 & 11 & 56 & 67 & 26 & 2 & 1 & 9 & 33 \\
\hline 1984 & 26 & 9 & 1 & 1 & 28 & 74 & 68 & 32 & 16 & 0 & 5 & 32 & 48 & 8 & 1 & 2 & 13 & 52 \\
\hline 1985 & 66 & 24 & 3 & 0 & 3 & 34 & 32 & 8 & 1 & 1 & 24 & 68 & 46 & 8 & 2 & 1 & 8 & 54 \\
\hline 1986 & 50 & 14 & 2 & 0 & 12 & 50 & 32 & 5 & 1 & 1 & 19 & 68 & 63 & 18 & 4 & 3 & 10 & 38 \\
\hline 1987 & 67 & 23 & 4 & 0 & 4 & 33 & 40 & 7 & 1 & 2 & 15 & 60 & 60 & 23 & 3 & 1 & 8 & 40 \\
\hline 1988 & 56 & 17 & 1 & 0 & 2 & 44 & 24 & 6 & 1 & 3 & 26 & 76 & 69 & 23 & 0 & 1 & 7 & 31 \\
\hline 1989 & 47 & 18 & 4 & 0 & 11 & 53 & 71 & 29 & 7 & 1 & 6 & 29 & 41 & 6 & 1 & 3 & 18 & 59 \\
\hline 1990 & 56 & 19 & 2 & 0 & 7 & 44 & 52 & 9 & 1 & 0 & 9 & 48 & 49 & 12 & 1 & 2 & 10 & 51 \\
\hline 1991 & 34 & 4 & 0 & 2 & 9 & 66 & 60 & 21 & 3 & 0 & 4 & 40 & 72 & 26 & 3 & 1 & 4 & 28 \\
\hline 1992 & 50 & 13 & 4 & 1 & 7 & 50 & 54 & 18 & 5 & 0 & 4 & 46 & 50 & 13 & 1 & 5 & 19 & 50 \\
\hline 1993 & 58 & 19 & 2 & 1 & 4 & 42 & 43 & 9 & 1 & 0 & 17 & 57 & 49 & 18 & 2 & 2 & 21 & 51 \\
\hline 1994 & 58 & 19 & 2 & 0 & 4 & 42 & 28 & 6 & 2 & 1 & 22 & 72 & 39 & 11 & 0 & 3 & 18 & 61 \\
\hline 1995 & 36 & 10 & 3 & 3 & 15 & 64 & 57 & 24 & 3 & 1 & 15 & 43 & 49 & 8 & 1 & 7 & 18 & 51 \\
\hline 1996 & 26 & 8 & 2 & 2 & 22 & 74 & 71 & 30 & 4 & 0 & 5 & 29 & 55 & 11 & 1 & 2 & 15 & 45 \\
\hline 1997 & 37 & 3 & 0 & 1 & 18 & 63 & 44 & 13 & 3 & 2 & 12 & 56 & 18 & 4 & 2 & 9 & 49 & 82 \\
\hline 1998 & 34 & 8 & 2 & 4 & 18 & 66 & 37 & 11 & 3 & 1 & 20 & 63 & 30 & 9 & 1 & 7 & 25 & 70 \\
\hline 1999 & 25 & 4 & 1 & 1 & 35 & 75 & 61 & 23 & 12 & 1 & 7 & 39 & 51 & 11 & 2 & 5 & 15 & 49 \\
\hline 2000 & 64 & 17 & 4 & 0 & 5 & 36 & 59 & 18 & 2 & 0 & 9 & 41 & 39 & 7 & 0 & 5 & 22 & 61 \\
\hline 2001 & 67 & 29 & 8 & 0 & 5 & 33 & 39 & 16 & 2 & 1 & 22 & 61 & 42 & 17 & 1 & 3 & 15 & 58 \\
\hline 2002 & 17 & 2 & 0 & 5 & 32 & 83 & 59 & 22 & 4 & 1 & 4 & 41 & 31 & 6 & 0 & 12 & 30 & 69 \\
\hline 2003 & 57 & 29 & 4 & 1 & 8 & 43 & 36 & 6 & 1 & 0 & 21 & 64 & 50 & 9 & 2 & 6 & 18 & 50 \\
\hline 2004 & 35 & 3 & 1 & 0 & 16 & 65 & 42 & 11 & 2 & 1 & 26 & 58 & 32 & 7 & 1 & 13 & 33 & 68 \\
\hline 2005 & 60 & 18 & 1 & 0 & 4 & 40 & 48 & 15 & 2 & 0 & 11 & 52 & 33 & 4 & 0 & 2 & 19 & 67 \\
\hline 2006 & 48 & 11 & 3 & 0 & 8 & 52 & 70 & 33 & 7 & 0 & 5 & 30 & 57 & 16 & 0 & 1 & 10 & 43 \\
\hline 2007 & 30 & 6 & 1 & 0 & 22 & 70 & 69 & 25 & 5 & 1 & 6 & 31 & 29 & 3 & 1 & 7 & 26 & 71 \\
\hline 2008 & 43 & 19 & 5 & 3 & 20 & 57 & 68 & 27 & 7 & 0 & 8 & 32 & 41 & 10 & 1 & 4 & 24 & 59 \\
\hline 2009 & 24 & 6 & 0 & 1 & 31 & 76 & 73 & 23 & 9 & 0 & 5 & 27 & 27 & 4 & 0 & 3 & 25 & 73 \\
\hline 2010 & 75 & 42 & 11 & 0 & 10 & 25 & 42 & 11 & 2 & 1 & 18 & 58 & 72 & 20 & 1 & 1 & 7 & 28 \\
\hline
\end{tabular}



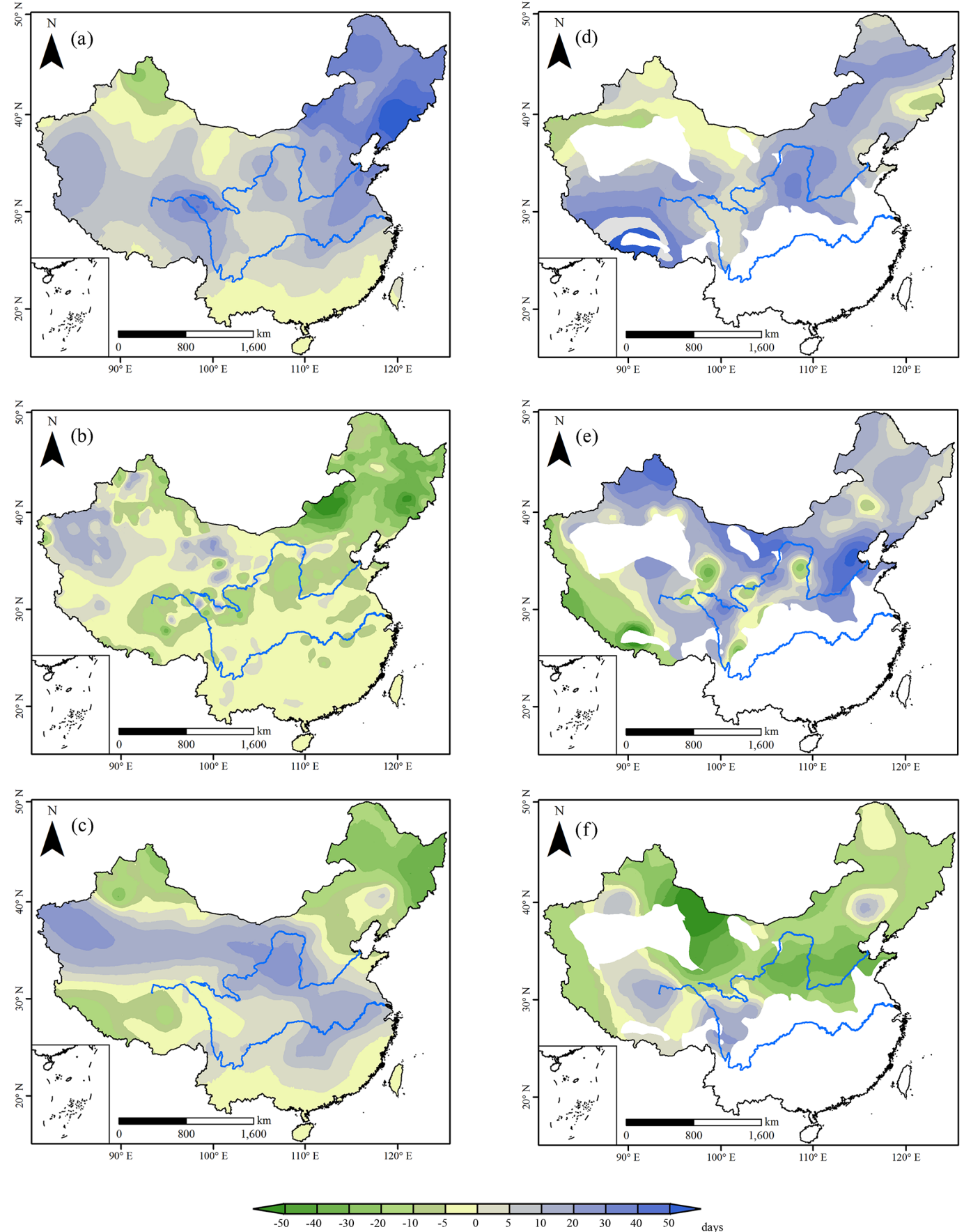

Figure 5. SCDs anomalies in 1957 (a), 2002 (b) and 2008 (c), anomaly of snow cover onset date (SCOD) in 2006 (d), and anomalies of snow cover end date (SCED) in 1957 (e) and 1997 (f).

Years with a positive anomaly of SCDs in the Tibetan Plateau include 1983 and 1990, whereas years with a negative anomaly of SCDs include 1965, 1969, and 2010 (Table 3). The climate in the Tibetan Plateau is affected by the Indian monsoon from the south, westerlies from the west, and the East Asian monsoon from the east (Yao et al., 2012). Therefore, there is a spatial difference in the SCDs within the
Tibetan Plateau, and a difference in the spatiotemporal distribution of snowstorms (Wang et al., 2013). Our results differ from the conclusions drawn by Dong et al. (2001), as they only used data from 26 stations, covering only a short period (1967-1996). 
Table 3. The same as Table 2, but only for the years with a positive (negative) anomaly of SCDs and only for the three major stable snow regions: Northeast China (78 stations), north Xinjiang (21 stations), and the Tibetan Plateau (63 stations).

\begin{tabular}{|c|c|c|c|c|c|c|c|c|c|c|c|c|c|c|c|c|c|c|}
\hline \multirow[b]{2}{*}{ Year } & \multicolumn{6}{|c|}{ Northeast China } & \multicolumn{6}{|c|}{ North Xinjiang } & \multicolumn{6}{|c|}{ Tibetan Plateau } \\
\hline & $\mathrm{P}$ & $1 \mathrm{SD}$ & $2 \mathrm{SD}$ & $-2 \mathrm{SD}$ & $-1 \mathrm{SD}$ & $\mathrm{N}$ & $\mathrm{P}$ & $1 \mathrm{SD}$ & $2 \mathrm{SD}$ & $-2 \mathrm{SD}$ & $-1 \mathrm{SD}$ & $\mathrm{N}$ & $\mathrm{P}$ & $1 \mathrm{SD}$ & $2 \mathrm{SD}$ & $-2 \mathrm{SD}$ & $-1 \mathrm{SD}$ & $\mathrm{N}$ \\
\hline 1957 & 98 & 72 & 16 & 0 & 0 & 2 & 22 & 0 & 0 & 2 & 33 & 78 & 74 & 52 & 13 & 0 & 4 & 26 \\
\hline 1959 & 2 & 0 & 0 & 15 & 73 & 98 & 88 & 38 & 0 & 0 & 0 & 12 & 37 & 11 & 3 & 0 & 6 & 63 \\
\hline 1960 & 39 & 14 & 1 & 0 & 26 & 61 & 100 & 88 & 29 & 0 & 0 & 0 & 23 & 0 & 0 & 3 & 30 & 77 \\
\hline 1963 & 11 & 0 & 0 & 6 & 41 & 89 & 26 & 0 & 0 & 5 & 26 & 74 & 20 & 0 & 0 & 0 & 28 & 80 \\
\hline 1965 & 66 & 24 & 0 & 1 & 16 & 34 & 21 & 0 & 0 & 0 & 37 & 79 & 12 & 4 & 0 & 4 & 50 & 88 \\
\hline 1967 & 16 & 0 & 0 & 14 & 59 & 84 & 78 & 22 & 0 & 0 & 6 & 22 & 23 & 6 & 0 & 0 & 15 & 77 \\
\hline 1969 & 21 & 1 & 0 & 15 & 43 & 79 & 78 & 28 & 0 & 0 & 6 & 22 & 4 & 0 & 0 & 6 & 53 & 96 \\
\hline 1973 & 89 & 60 & 4 & 0 & 0 & 11 & 42 & 0 & 0 & 5 & 11 & 58 & 36 & 11 & 2 & 0 & 21 & 64 \\
\hline 1974 & 55 & 18 & 0 & 3 & 21 & 45 & 5 & 0 & 0 & 21 & 58 & 95 & 38 & 3 & 0 & 2 & 14 & 62 \\
\hline 1977 & 73 & 32 & 4 & 0 & 5 & 27 & 95 & 74 & 0 & 0 & 5 & 5 & 36 & 19 & 7 & 0 & 7 & 64 \\
\hline 1980 & 65 & 18 & 1 & 0 & 8 & 35 & 95 & 63 & 5 & 0 & 0 & 5 & 45 & 10 & 2 & 0 & 3 & 55 \\
\hline 1983 & 62 & 23 & 3 & 0 & 3 & 38 & 26 & 0 & 0 & 0 & 21 & 74 & 95 & 60 & 19 & 0 & 0 & 5 \\
\hline 1988 & 70 & 23 & 0 & 0 & 3 & 30 & 100 & 68 & 11 & 0 & 0 & 0 & 52 & 22 & 5 & 0 & 2 & 48 \\
\hline 1990 & 40 & 0 & 0 & 0 & 11 & 60 & 32 & 5 & 0 & 0 & 21 & 68 & 81 & 41 & 3 & 0 & 0 & 19 \\
\hline 1994 & 94 & 29 & 1 & 0 & 0 & 6 & 95 & 53 & 0 & 0 & 0 & 5 & 46 & 14 & 2 & 0 & 11 & 54 \\
\hline 1995 & 33 & 1 & 0 & 3 & 15 & 67 & 5 & 0 & 0 & 21 & 74 & 95 & 75 & 42 & 11 & 0 & 0 & 25 \\
\hline 1998 & 4 & 0 & 0 & 14 & 64 & 96 & 63 & 5 & 0 & 5 & 11 & 37 & 82 & 39 & 12 & 0 & 0 & 18 \\
\hline 2002 & 4 & 0 & 0 & 19 & 63 & 96 & 26 & 0 & 0 & 5 & 21 & 74 & 22 & 2 & 0 & 0 & 15 & 78 \\
\hline 2008 & 7 & 0 & 0 & 11 & 48 & 93 & 5 & 0 & 0 & 5 & 47 & 95 & 59 & 6 & 0 & 2 & 14 & 41 \\
\hline 2010 & 92 & 69 & 17 & 0 & 3 & 8 & 100 & 67 & 11 & 0 & 0 & 0 & 15 & 6 & 0 & 2 & 50 & 85 \\
\hline
\end{tabular}

Table 4. Significance of trends according to the Mann-Kendall test of SCDs, SCOD, and SCED, significance of relationships among SCDs, SCOD, SCED, respectively, with TBZD, significance of relationship between SCDs and MAT, and significance of relationship between SCDs and AO (296 stations in total). All of them have two significance levels, 90 and $95 \%$.

\begin{tabular}{ll|lll|lll|lll}
\hline & & \multicolumn{3}{|c|}{ SCDs } & \multicolumn{3}{|c|}{ SCOD } & \multicolumn{3}{|c}{ SCED } \\
& & $95 \%$ & $90 \%$ & $\mathrm{I}^{*}$ & $95 \%$ & $90 \%$ & $\mathrm{I}^{*}$ & $95 \%$ & $90 \%$ & $\mathrm{I}^{*}$ \\
\hline \multirow{2}{*}{ Trend } & Positive & 19 & 37 & 125 & 178 & 196 & 74 & 1 & 3 & 37 \\
& Negative & 26 & 35 & 99 & 5 & 8 & 18 & 72 & 103 & 153 \\
\hline \multirow{2}{*}{ TBZD } & Positive & 124 & 154 & 126 & 0 & 1 & 50 & 72 & 99 & 170 \\
& Negative & 1 & 1 & 15 & 61 & 87 & 158 & 0 & 2 & 25 \\
\hline \multirow{2}{*}{ MAT } & Positive & 0 & 2 & 22 & & & & & & \\
& Negative & 114 & 148 & 124 & & & & & & \\
\hline AO & Positive & 31 & 45 & 90 & & & & & & \\
& Negative & 33 & 48 & 113 & & & & & & \\
\hline
\end{tabular}

Note: $I^{*}$ represents insignificant trends or relations.

\subsubsection{SCD trends}

Changing trends of annual SCDs are examined, as shown in Fig. 6a, and summarised in Table 4. Among the 296 stations, there are 35 stations $(12 \%)$ with a significant negative trend, and 37 stations $(13 \%)$ with a significant positive trend (both at the $90 \%$ level), while $75 \%$ of stations show no significant trends. The SCDs exhibit a significant downward trend in the Xiaoxingganling, the Changbai Mountains, the Shandong peninsula, the Qilian Mountains, the North Tianshan Mountains, and the peripheral zones in the south and eastern Tibetan Plateau (Fig. 6a). For example, the SCDs decreased by 50 days from 1955 to 2010 at the Kuandian station in Northeast China, 28 days from 1954 to 2010 at the Hongli- uhe station in Xinjiang, and 10 days from 1958 to 2010 at the Gangcha station on the Tibetan Plateau (Fig. 7a-c).

The SCDs in the Bayan Har Mountains, the Anemaqen Mountains, the Inner Mongolia Plateau, and the Northeast Plain, exhibit a significant upward trend (Fig. 6a). For example, at the Shiqu station on the eastern border of the Tibetan Plateau, the SCDs increased 26 days from 1960 to 2010 (Fig. 7d). The coexistence of negative and positive trends in the change of SCDs was also reported by Bulygina et al. (2009) and Wang and Li (2012). 

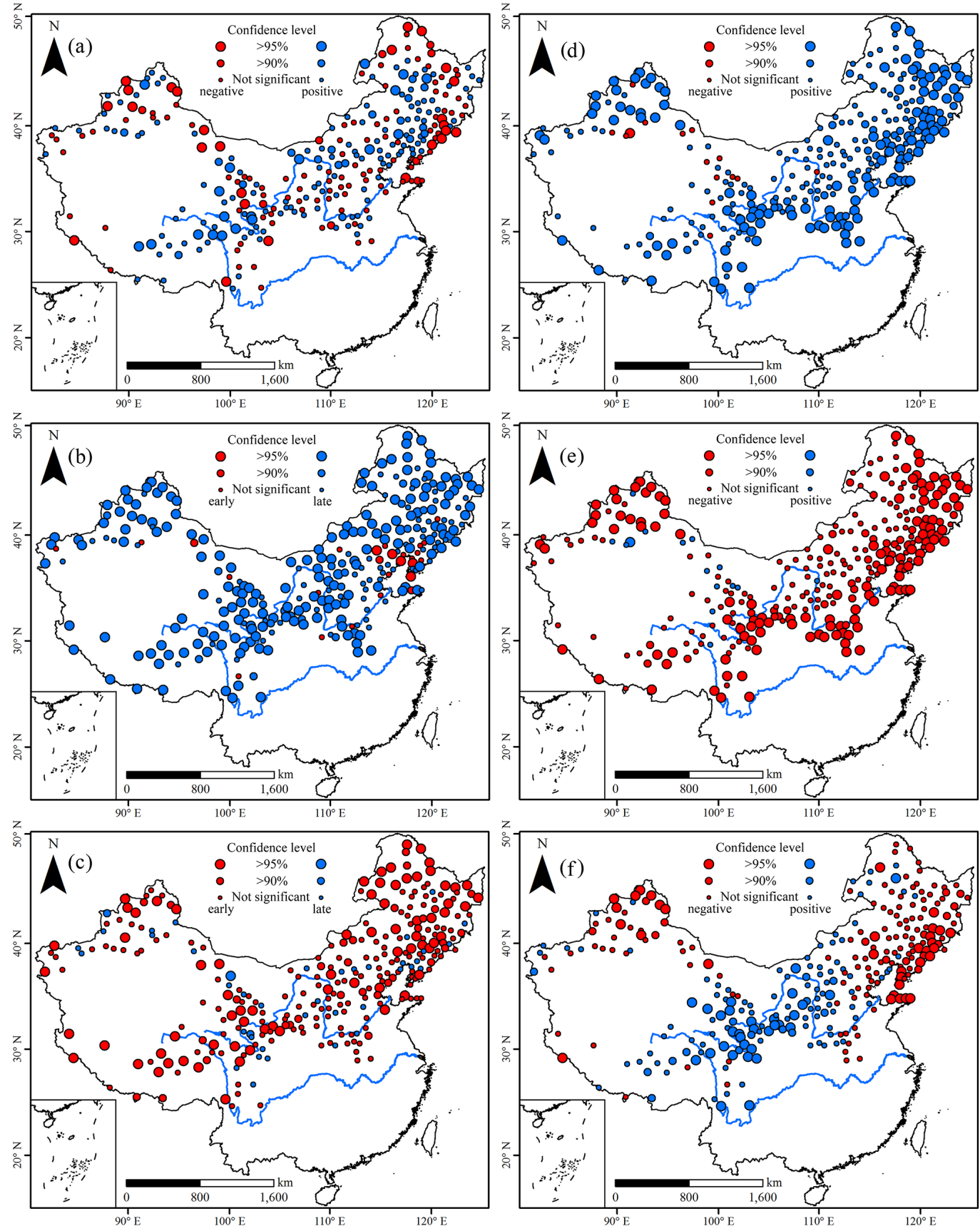

Figure 6. Significance of trends according to the Mann-Kendall test of SCDs (a), SCOD (b), and SCED (c) from the 296 stations with more than 10 annual mean SCDs, significance of relationship between the SCDs and days with temperature below $0{ }^{\circ} \mathrm{C}$ (TBZD) (d), significance of relationship between the SCDs and mean air temperature (MAT) (e), and significance of relationship between the SCDs and Arctic Oscillation (AO) index (f).

\subsection{Spatiotemporal variations of SCOD}

\subsubsection{SCOD variations}

The SCOD is closely related to both latitude and elevation (Fig. 8a). For example, snowfall begins in September on the
Tibetan Plateau, in early or middle October on the Daxinganling, and in middle or late October on the Altai Mountains in Xinjiang. The SCOD also varies from one year to another (Table 2). Using the definition of a year with a positive (negative) anomaly of SCDs, as introduced before (i.e. $70 \%$ stations with positive (negative) SCOD anomaly and $30 \%$ sta- 

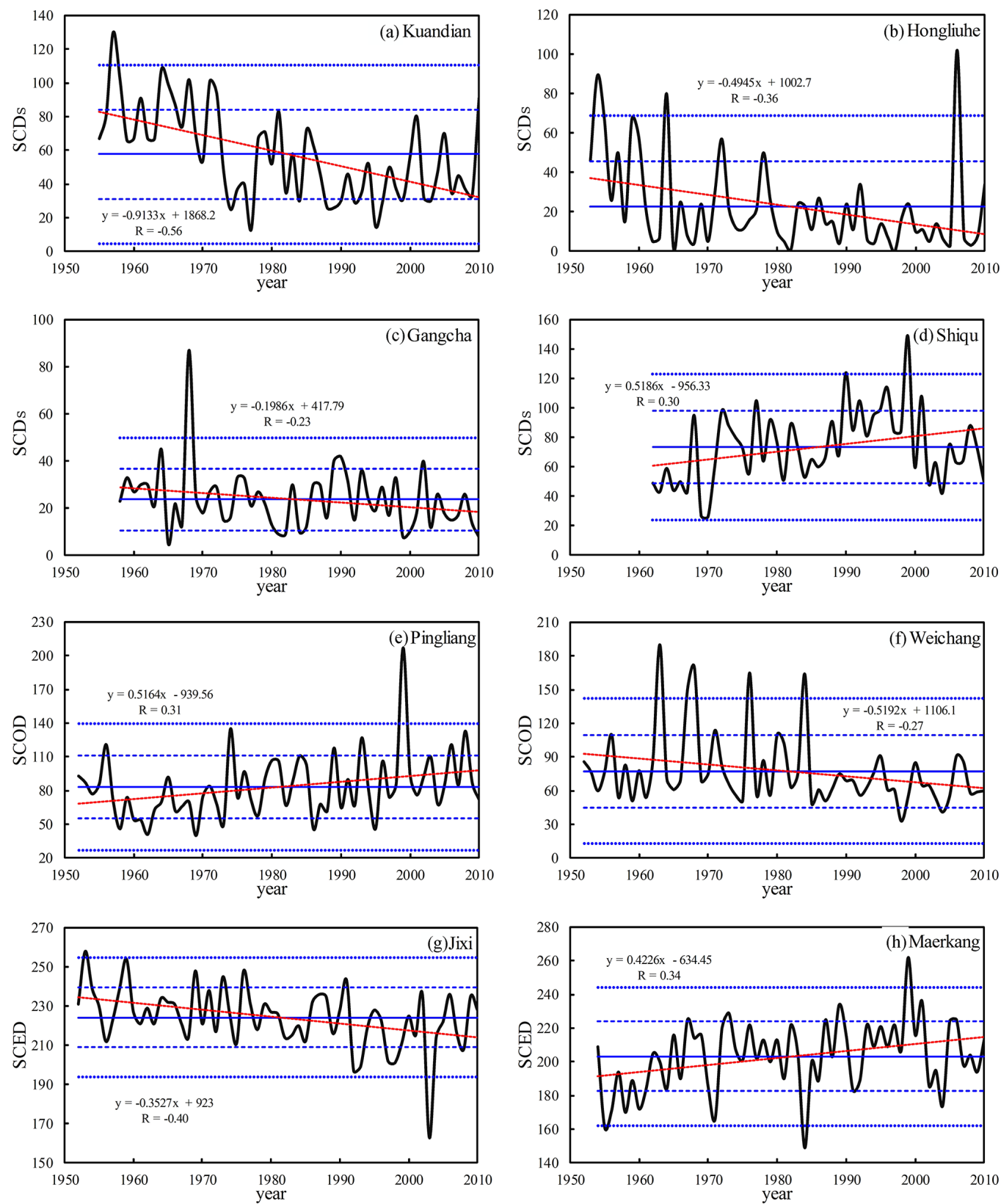

Figure 7. Variations in SCDs at Kuandian $\left(40^{\circ} 43^{\prime} \mathrm{N}, 124^{\circ} 47^{\prime} \mathrm{E} ; 260.1 \mathrm{~m}\right)$ (a), Hongliuhe $\left(41^{\circ} 32^{\prime} \mathrm{N}, 94^{\circ} 40^{\prime} \mathrm{E} ; 1573.8 \mathrm{~m}\right)(\mathbf{b})$, Gangcha $\left(37^{\circ} 20^{\prime} \mathrm{N}, 100^{\circ} 08^{\prime} \mathrm{E} ; 3301.5 \mathrm{~m}\right)$ (c), and Shiqu $\left(32^{\circ} 59^{\prime} \mathrm{N}, 98^{\circ} 06^{\prime} \mathrm{E} ; 4533.0 \mathrm{~m}\right)$ (d); SCOD at Pingliang $\left(35^{\circ} 33^{\prime} \mathrm{N}, 106^{\circ} 40^{\prime} \mathrm{E} ; 1412.0 \mathrm{~m}\right)(\mathbf{e})$ and Weichang $\left(41^{\circ} 56^{\prime} \mathrm{N}, 117^{\circ} 45^{\prime} \mathrm{E} ; 842.8 \mathrm{~m}\right)$ (f); and SCED at Jixi $\left(45^{\circ} 18^{\prime} \mathrm{N}, 130^{\circ} 56^{\prime} \mathrm{E} ; 280.8 \mathrm{~m}\right)(\mathbf{g})$, and $\mathrm{Maerkang}\left(31^{\circ} 54^{\prime} \mathrm{N}, 102^{\circ} 54^{\prime} \mathrm{E}\right.$; $2664.4 \mathrm{~m})(\mathbf{h})$. (The unit on the $y$ axis in the panels (e), (f), (g), and (h) denotes the Julian day using 1 September as reference).

tions with SCOD larger (smaller) than the mean $\pm 1 \mathrm{SD}$ ), we consider a given year as a late (early) SCOD year. Two years, 1996 and 2006, can be considered as late SCOD years on a large scale (Table 2), especially in 2006, in East China and the Tibetan Plateau (Fig.5d). Only 1 year, 1982, can be considered as an early SCOD year.

\subsubsection{SCOD trends}

There are 196 stations (66\%) with a significant trend of late SCOD, and eight stations (3\%) with a significant trend of early SCOD (both at the $90 \%$ level), while $31 \%$ of the stations show no significant trends (Table 4). The SCOD in the major snow regions in China exhibits a significant trend towards late SCOD (Fig. 6b). These significantly late trends 

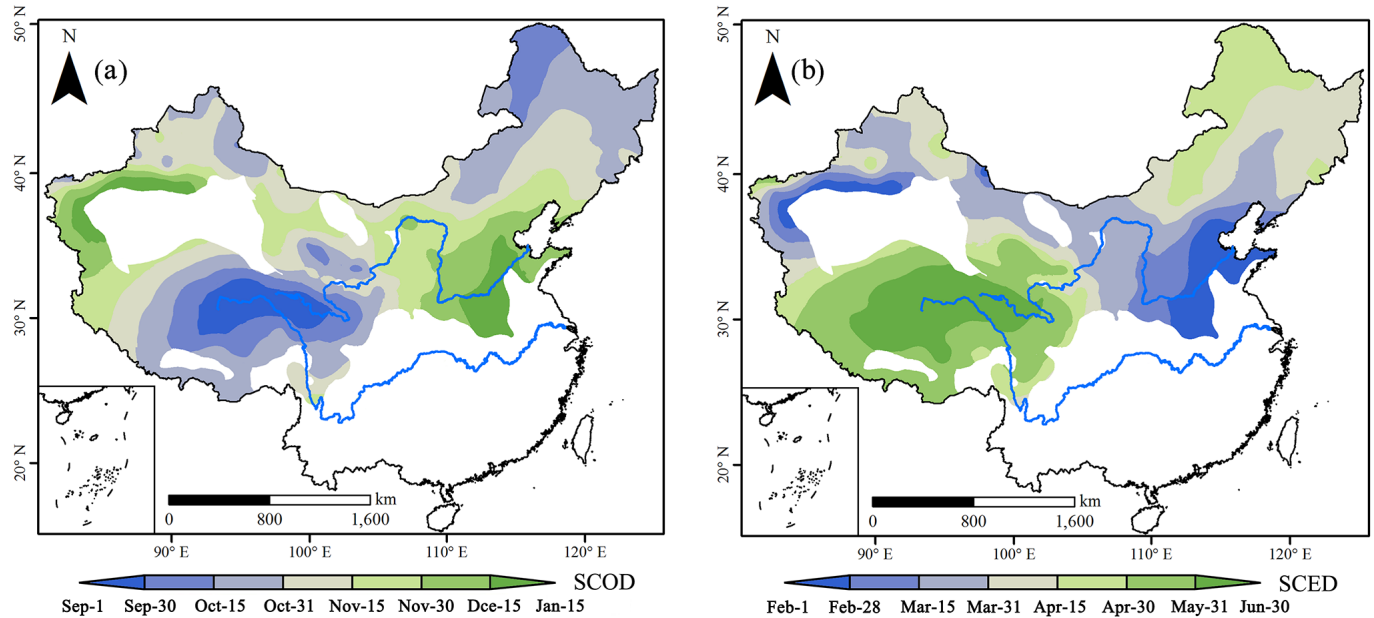

Figure 8. Spatial distribution of SCOD (a) and SCED (b) based on the stations with an average of more than 10 SCDs.

dominate the major snow regions in China. In particular, the late SCOD in Northeast China is consistent with a previous study (Li et al., 2009). Only the SCOD in the east Liaoning Bay region exhibits a significant trend towards early SCOD. For example, the SCOD at the Pingliang station in Gansu province shows a late rate of 5.2 days per decade from 1952 to 2010, but the SCOD at the Weichang station in Hebei province shows an early rate of 5.2 days per decade from 1952 to 2010 (Fig. 7e-f).

\subsection{Spatiotemporal variations of SCED}

\subsubsection{SCED variations}

The pattern of SCED is similar to that of SCOD (Fig. 8b), i.e. places with early snowfall normally show late snowmelt, while places with late snowfall normally show early snowmelt. Like the SCOD, temporal variations of SCED are large (Table 2). Using the same standard for defining the SCOD anomaly, we judge a given year as a late (early) SCED year. Three years, 1957, 1976 and 1979, can be considered as late SCED years on a large scale (Table 2). It is evident that 1957 was a typical year whose SCED was late, which was also the reason for the great SCDs (Fig. 5a and e). The SCED in 1997 was early for almost all of China except for the Tibetan Plateau, western Tianshan Mountains, and western Liaoning (Fig. 5f).

\subsubsection{SCED trends}

For the SCED, there are 103 stations (35\%) with a significantly early trend (at the $90 \%$ level), while $64 \%$ of stations show no significant trends (Table 4). The major snow regions in China all show early SCED, significant for Northeast China, north Xinjiang, and the Tibetan Plateau (Fig. 6c). The tendency of late SCED is limited, with only three stations
(1\%) showing a significant trend. For example, the SCED at the Jixi station in Northeast China shows an early rate of 3.5 days per decade from 1952 to 2010, while the SCED at the Maerkang station in Sichuan province shows a late rate of 4.2 days per decade from 1954 to 2010 (Fig. $7 \mathrm{~g}-\mathrm{h}$ ).

\section{Discussion}

In the context of global warming, 196 stations $(66 \%)$ show significantly late SCOD, and 103 stations (35\%) show significantly early SCED, all at the $90 \%$ confidence level. It is not necessary for one station to show both significantly late SCOD and early SCED. This explains why only $12 \%$ of stations show a significantly negative SCDs trend, while $75 \%$ of stations show no significant change in the trends of SCDs. The latter is inconsistent with the overall shortening of the snow period in the Northern Hemisphere reported by Choi et al. (2010). One reason could be the different time periods used in the two studies, 1972-2007 in Choi et al. (2010) as compared to 1952-2010 in this study. Below, we discuss the possible connections between the spatiotemporal variations of snow cover and the warming climate and changing $\mathrm{AO}$.

\subsection{Relationship with TBZD}

The number of days with temperature below $0{ }^{\circ} \mathrm{C}$ (TBZD) plays an important role in the SCDs. There are 280 stations (95\% of 296 stations) showing positive correlations between TBZD and SCDs, with 154 of them (52\%) having significantly positive correlations (Table 4, Fig. 6d). For example, there is a significantly positive correlation between SCDs and TBZD at the Chengshantou station (Fig. 9a). Therefore, generally speaking, the smaller the TBZD, the shorter the SCDs.

For the SCOD, there are 245 stations with negative correlations with TBZD, accounting for $83 \%$ of 296 stations, 

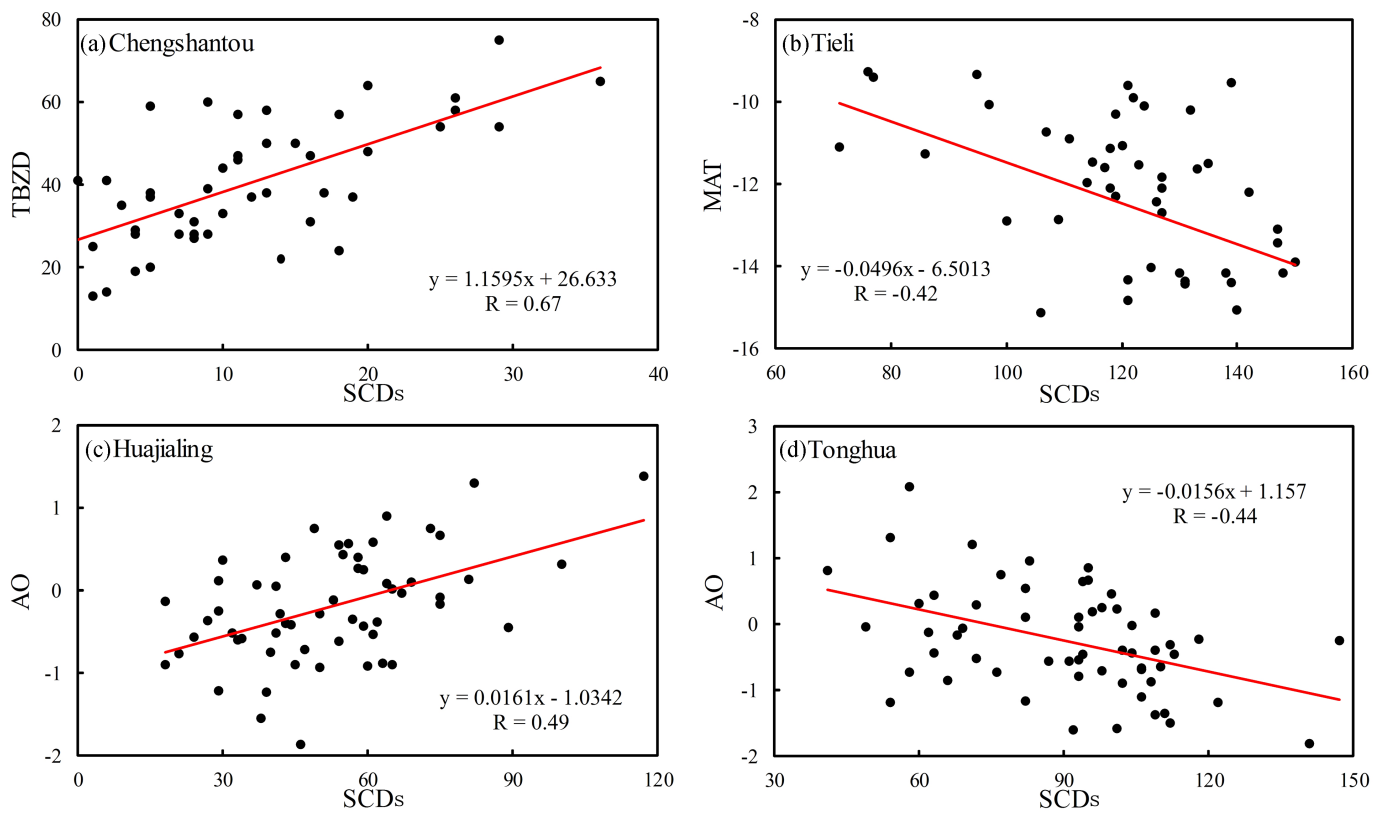

Figure 9. SCDs relationships with TBZD at Chengshantou $\left(37^{\circ} 24^{\prime} \mathrm{N}, 122^{\circ} 41^{\prime} \mathrm{E} ; 47.7 \mathrm{~m}\right)(\mathbf{a})$, MAT at Tieli $\left(46^{\circ} 59^{\prime} \mathrm{N}, 128^{\circ} 01^{\prime} \mathrm{E} ; 210.5 \mathrm{~m}\right)$ (b), and $\mathrm{AO}$ index at Huajialing $\left(35^{\circ} 23^{\prime} \mathrm{N}, 105^{\circ} 00^{\prime} \mathrm{E} ; 2450.6 \mathrm{~m}\right)$ (c) and Tonghua $\left(41^{\circ} 41^{\prime} \mathrm{N}, 125^{\circ} 54^{\prime} \mathrm{E} ; 402.9 \mathrm{~m}\right)(\mathbf{d})$.

whereas only 51 stations (17\%) show positive correlations (Table 4). This means that for smaller TBZD, the SCOD is later. For the SCED, there are 269 stations with positive correlations, accounting for $91 \%$ of 296 stations, whereas only 27 stations (9\%) have negative correlations. This means that for smaller TBZD, the SCED is earlier.

Very similar results are found for the MAT (Table 4, Fig. 6e), and Fig. 9b shows an example (the Tieli station).

\subsection{Relationship with AO}

Although the AO index has shown a strong positive trend in the past decades (Thompson et al., 2000), its impact on the SCDs in China is spatially distinctive. Positive correlations (46\% of 296 stations) are found in the eastern Tibetan Plateau and the Loess Plateau (Table 4, Fig. 6f), and Fig. 9c shows an example (the Huajialing station). Negative correlations (54\% of 296 stations) exist in north Xinjiang, Northeast China, and the Shandong peninsula, and Fig. 9d shows an example (the Tonghua station).

\section{Conclusion}

This study examines the snow cover change based on 672 stations in 1952-2010 in China. Specifically, the 296 stations with more than 10 annual mean SCDs are used to study the changing trends of SCDs, SCOD, and SCED, and SCD relationships with TBZD, MAT, and AO index during snow seasons. Some important results are summarised below.
Northeast China, north Xinjiang, and the Tibetan Plateau are the three major snow regions. The overall inter-annual variability of SCDs is large in China. The years with a positive anomaly of SCDs in China include 1955, 1957, 1964, and 2010, while the years with a negative anomaly of SCDs are $1953,1965,1999,2002$, and 2009 . Only $12 \%$ of stations show a significantly negative SCDs trend, while $75 \%$ of stations show no significant SCDs trends. Our analyses indicate that the distribution pattern and trends of SCDs in China are very complex and are not controlled by any single climate variable examined (i.e. TBZD, MAT, or AO), but by a combination of multiple variables.

It is found that significantly late SCOD occurs in nearly the whole of China except for the east Liaoning Bay region; significantly early SCED occurs in nearly all major snow regions in China. Both the SCOD and SCED are closely related to the TBZD and MAT, and are mostly controlled by local latitude and elevation. Owing to global warming since the 1950s, the reduced TBZD and increased MAT are the main reasons for overall late SCOD and early SCED, although it is not necessary for one station to experience both significantly late SCOD and early SCED. This explains why only $12 \%$ of stations show significantly negative trends in SCDs, while $75 \%$ of stations show no significant SCDs trends.

Long-duration, consistent records of snow cover and depth are rare in China because of many challenges associated with taking accurate and representative measurements, especially in western China; the station density and metric choice also vary with time and locality. Therefore, more accurate and reliable observation data are needed to further analyse the spa- 
tiotemporal distribution and features of snow cover phenology. Atmospheric circulation causes variability in the snow cover phenology, and its effect requires deeper investigations.

Acknowledgements. This work is financially supported by the Program for National Nature Science Foundation of China (no. 41371391), and the Program for the Specialized Research Fund for the Doctoral Program of Higher Education of China (no. 20120091110017). This work is also partially supported by the Collaborative Innovation Center of Novel Software Technology and Industrialization. We would like to thank the National Climate Center of China (NCC) in Beijing for providing valuable climate data sets. We thank the three anonymous reviewers and the editor for valuable comments and suggestions that greatly improved the quality of this paper.

Edited by: H.-J. Hendricks Franssen

\section{References}

Alexandersson, H. and Moberg, A.: Homogenization of Swedish temperature data Part 1: homogeneity test for linear trends, Int. J. Climatol., 17, 25-34, 1997.

An, D., Li, D., Yuan, Y., and Hui, Y.: Contrast between snow cover data of different definitions, J. Glaciol. Geocrol., 31, 1019-1027, 2009.

Barnett, T. P., Dumenil, L., and Latif, M.: The effect of Eurasian snow cover on regional and global climate variations, J. Atmos. Sci., 46, 661-685, 1989.

Beniston, M: Variations of snow depth and duration in the Swiss Alps over the last 50 years: Links to changes in large-scale climatic forcings, Clim. Change, 36, 281-300, 1997.

Birsan, M. V. and Dumitrescu, A.: Snow variability in Romania in connection to large-scale atmospheric circulation, Int. J. Climatol., 34, 134-144, 2014.

Bolsenga, S. J. and Norton, D. C.: Maximum snowfall at long-term stations in the U.S./Canadian Great Lakes, Nat. Hazards, 5, 221232, 1992.

Brown, R. D. and Robinson, D. A.: Northern Hemisphere spring snow cover variability and change over 1922-2010 including an assessment of uncertainty, The Cryosphere, 5, 219-229, doi:10.5194/tc-5-219-2011, 2011.

Bulygina, O. N., Razuvaev, V. N., and Korshunova, N. N.: Changes in snow cover over Northern Eurasia in the last few decades, Environ. Res. Lett., 4, 045026, doi:10.1088/1748-9326/4/4/045026, 2009.

Chen, S., Chen, W., and Wei, K.: Recent trends in winter temperature extremes in eastern China and their relationship with the Arctic Oscillation and ENSO, Adv. Atmos. Sci., 30, 1712-1724, 2013.

China Meteorological Administration: Specifications for Surface Meteorological Observations, Beijing, China Meteorological Press, 1-62, 2003.

Choi, G., Robinson, D. A., and Kang, S.: Changing Northern Hemisphere snow seasons, J. Climate, 23, 5305-5310, 2010.
Ciach, G. J. and Krajewski, W. F.: Analysis and modeling of spatial correlation structure in small-scale rainfall in Central Oklahoma, Adv. Water Resour., 29, 1450-1463, 2006.

Déry, S. J. and Brown, R. D.: Recent Northern Hemisphere snow cover extent trends and implications for the snow-albedo feedback, Geophys. Res. Lett., 34, L22504, doi:10.1029/2007GL031474, 2007.

Dong, A., Guo, H., Wang, L., and Liang, T.: A CEOF analysis on variation about yearly snow days in Northern Xinjiang in recent 40 years, Plateau Meteorol., 23, 936-940, 2004.

Dong, W., Wei, Z., and Fan, J.: Climatic character analysis of snow disasters in east Qinghai-Xizang Plateau livestock farm, Plateau Meteorol., 20, 402-406, 2001.

Dyer, J. L. and Mote, T. L.: Spatial variability and trends in observed snow depth over North America, Geophys. Res. Lett., 33, L16503, doi:10.1029/2006GL027258, 2006.

Fang, S., Qi, Y., Han, G., Zhou, G., and Cammarano, D.: Meteorological drought trend in winter and spring from 1961 to 2010 and its possible impacts on wheat in wheat planting area of China, Sci. Agr. Sin., 47, 1754-1763, 2014.

Gao, H.: China's snow disaster in 2008, who is the principal player?, Int. J. Climatol., 29, 2191-2196, 2009.

Gong, D. Y., Wang, S. W., and Zhu, J. H.: East Asian winter monsoon and Arctic oscillation, Geophys. Res. Lett., 28, 2073-2076, 2001.

Groisman, P. Y., Karl, T. R., and Knight, R. W.: Observed impact of snow cover on the heat-balance and the rise of continental spring temperatures, Science, 263, 198-200, 1994.

Habib, E., Krajewski, W. F., and Ciach, G. J.: Estimation of rainfall interstation correlation, J. Hydrometeorol., 2, 621-629, 2001.

Hantel, M., Ehrendorfer, M., and Haslinger, A.: Climate sensitivity of snow cover duration in Austria, Int. J. Climatol., 20, 615-640, 2000.

Hao, L., Wang, J., Man, S., and Yang, C.: Spatio-temporal change of snow disaster and analysis of vulnerability of animal husbandry in China, J. Nat. Disaster, 11, 42-48, 2002.

$\mathrm{Hu}, \mathrm{H}$. and Liang, L.: Temporal and spatial variations of snowfall in the east of Qinghai-Tibet Plateau in the last 50 years, Acta Geogr. Sin., 69, 1002-1012, 2014.

Jeong, J. H. and Ho, C. H.: Changes in occurrence of cold surges over East Asia in association with Arctic oscillation, Geophys. Res. Lett., 32, L14704, doi:10.1029/2005GL023024, 2005.

Ji, Z. and Kang, S.: Projection of snow cover changes over China under RCP scenarios Clim. Dyn., 41, 589-600, 2013.

Ke, C. Q. and Li, P. J.: Spatial and temporal characteristics of snow cover over the Tibetan plateau, Acta Geogr. Sin., 53, 209-215, 1998.

Ke, C. Q. and Liu, X.: MODIS-observed spatial and temporal variation in snow cover in Xinjiang, China, Clim. Res., 59, 15-26, 2014.

Ke, C. Q., Yu, T., Yu, K., Tang, G. D., and King, L.: Snowfall trends and variability in Qinghai, China, Theor. Appl. Climatol., 98, 251-258, 2009.

Lehning, M., Grünewald, T., and Schirmer, M.: Mountain snow distribution governed by an altitudinal gradient and terrain roughness, Geophys. Res. Lett., 38, L19504, doi:10.1029/2011GL048927, 2011. 
Li, D., Liu, Y., Yu, H. and Li, Y.: Spatial-temporal variation of the snow cover in Heilongjiang Province in 1951-2006, J. Glaciol. Geocrol., 31, 1011-1018, 2009.

Li, P. J.: Dynamic characteristic of snow cover in western China, Acta Meteorol. Sin., 48, 505-515, 1993.

Li, P. J.: A preliminary study of snow mass variations over past 30 years in China, Acta Geogr. Sin., 48, 433-437, 1990.

Li, P. J. and Mi, D.: Distribution of snow cover in China, J. Glaciol. Geocrol., 5, 9-18, 1983.

Liang, T. G., Huang, X. D., Wu, C. X., Liu, X. Y., Li, W. L., Guo, Z. G., and Ren, J. Z.: An application of MODIS data to snow cover monitoring in a pastoral area: A case study in Northern Xinjiang, China, Remote Sens. Environ., 112, 1514-1526, 2008.

Liu, Y., Ren, G., and Yu, H.: Climatology of Snow in China, Sci. Geogr. Sin., 32, 1176-1185, 2012.

Llasat, M. C., Turco, M., Quintana-Seguí, P., and Llasat-Botija, M.: The snow storm of 8 March 2010 in Catalonia (Spain): a paradigmatic wet-snow event with a high societal impact, Nat. Hazards Earth Syst. Sci., 14, 427-441, doi:10.5194/nhess-14-427-2014, 2014.

Lü, J. M., Ju, J. H., Kim, S. J., Ren, J. Z., and Zhu, Y. X.: Arctic Oscillation and the autumn/winter snow depth over the Tibetan Plateau, J. Geophys. Res., 113, D14117, 2008.

Ma, L. and Qin, D.: Temporal-spatial characteristics of observed key parameters of snow cover in China during 1957-2009, Sci. Cold Arid Reg., 4, 384-393, 2012.

Marty, C.: Regime shift of snow days in Switzerland, Geophys. Res. Lett., 35, L12501, doi:10.1029/2008GL033998, 2008.

Morán-Tejeda, E., López-Moreno, J. I., and Beniston, M.: The changing roles of temperature and precipitation on snowpack variability in Switzerland as a function of altitude, Geophys. Res. Lett., 40, 2131-2136, 2013.

Pederson, G. T., Betancourt, J. L., and Gregory, J. M.: Regional patterns and proximal causes of the recent snowpack decline in the Rocky Mountains, U.S., Geophys. Res. Lett., 40, 1811-1816, 2013.

Peings, Y., Brun, B., Mauvais, V., and Douville, H.: How stationary is the relationship between Siberian snow and Arctic Oscillation over the 20th century, Geophys. Res. Lett., 40, 183-188, 2013.

Peng, S., Piao, S., Ciais, P., Friedlingstein, P., Zhou, L., and Wang, T.: Change in snow phenology and its potential feedback to temperature in the Northern Hemisphere over the last three decades, Environ. Res. Lett., 8, 014008, doi:10.1088/17489326/8/1/014008, 2013.

Qin, D., Liu, S., and Li, P.: Snow cover distribution, variability, and response to climate change in western China, J. Climate, 19, 1820-1833, 2006.

Ren, G. Y., Guo, J., Xu, M. Z., Chu, Z. Y., Zhang, L., Zou, X. K., Li, Q. X., and Liu, X. N.: Climate changes of China's mainland over the past half century, Acta. Meteorol. Sin., 63, 942-956, 2005.

Robinson, D. A. and Dewey, K. F.: Recent secular variations in the extent of northern hemisphere snow cover, Geophys. Res. Lett., 17, 1557-1560, 1990.

Scherrer, S. C., Appenzeller, C., and Laternser, M.: Trends in Swiss Alpine snow days: The role of local- and largescale climate variability, Geophys. Res. Lett., 31, L13215, doi:10.1029/2004GL020255, 2004.
Scherrer, S. C., and Appenzeller, C.: Swiss Alpine snow pack variability: major patterns and links to local climate and large-scale flow, Clim. Res., 32, 187-199, 2006.

Scherrer, S. C., Wüthrich, C., Croci-Maspoli, M., Weingartner, R., and Appenzeller, C.: Snow variability in the Swiss Alps 1864 2009, Int. J. Clim., 33, 3162-3173, doi:10.1002/joc.3653, 2013.

Serquet, G., Marty, C., Dulex, J.-P., and Rebetez, M.: Seasonal trends and temperature dependence of the snowfall/precipitationday ratio in Switzerland, Geophys. Res. Lett., 38, L07703, doi:10.1029/2011GL046976, 2011.

Shi, Y., Gao, X., Wu, J., and Giorgi, F.: Changes in snow cover over China in the 21 st century as simulated by a high resolution regional climate model, Environ. Res. Lett., 6, 045401, doi:10.1088/1748-9326/6/4/045401, 2011.

Tang, X., Yan, X., Ni, M., and Lu, Y.: Changes of the snow cover days on Tibet Plateau in last 40 years, Acta. Geogr. Sin., 67, 951959, 2012.

Thompson, D. W. J. and Wallace, J. M.: The Arctic oscillation signature in the wintertime geopotential height and temperature fields, Geophys. Res. Lett., 25, 1297-1300, 1998.

Thompson, D. W. J., Wallace, J. M., and Hegerl, G. C.: Annular modes in the extratropical circulation, part II: Trends, J. Climate, 13, 1018-1036, 2000.

Wang, C. and Li, D.: Spatial-temporal variations of the snow cover days and the maximum depth of snow cover in China during recent 50 years, J. Glaciol. Geocrol., 34, 247-256, 2012.

Wang, C., Wang, Z., and Cui, Y.: Snow cover of China during the last 40 years: Spatial distribution and interannual variation, J. Glaciol. Geocrol., 31, 301-310, 2009.

Wang, L., Gao, G., Zhang, Q., Sun, J. M., Wang, Z. Y., Zhao, Y., Zhao, S. S., Chen, X. Y., Chen, Y., Wang, Y. M., Chen, L. J., and Gao, H.: Characteristics of the extreme low-temperature, heavy snowstorm and freezing disasters in January 2008 in China, Meteorol. Mon., 34, 95-100, 2008.

Wang, Q., Zhang, C., Liu, J., and Liu, W.: The changing tendency on the depth and days of snow cover in Northern Xinjiang, Adv. Clim. Change Res., 5, 39-43, 2009.

Wang, W., Liang, T., Huang, X., Feng, Q., Xie, H., Liu, X., Chen, M., and Wang, X.: Early warning of snow-caused disasters in pastoral areas on the Tibetan Plateau, Nat. Hazards Earth Syst. Sci., 13, 1411-1425, doi:10.5194/nhess-13-1411-2013, 2013.

Wu, B. Y. and Wang, J.: Winter Arctic oscillation, Siberian high and East Asian winter monsoon, Geophys. Res. Lett., 29, 1897 , doi:10.1029/2002GL015373, 2002.

Xi, Y., Li, D., and Wang, W.: Study of the temporal-spatial characteristics of snow covers days in Hetao and its vicinity, J. Glaciol. Geocrol., 31, 446-456, 2009.

$\mathrm{Xu}, \mathrm{L} ., \mathrm{Li}, \mathrm{D}$. , and Hu, Z.: Relationship between the snow cover day and monsoon index in Tibetan Plateau, Plateau Meterol., 29, 1093-1101, 2010.

Yang, H., Yang, D., Hu, Q., and Lv, H.: Spatial variability of the trends in climatic variables across China during 1961-2010, Theor. Appl. Climatol., 120, 773-783, 2015.

Yao, T., Thompson, L., Yang, W., Yu, W., Gao, Y., Guo, X., Yang, X., Duan, K., Zhao, H., Xu, B., Pu, J., Lu, A., Xiang, Y., Kattel, D. B., and Joswiak, D.: Different glacier status with atmospheric circulations in Tibetan Plateau and surroundings, Nature Clim. Change, 2, 663-667, 2012. 
Ye, H. and Ellison, M.: Changes in transitional snowfall season length in northern Eurasia, Geophys. Res. Lett., 30, 1252, doi:10.1029/2003GL016873, 2003.

You, Q., Kang, S., Ren, G., Fraedrich, K., Pepin, N., Yan, Y., and Ma, L.: Observed changes in snow depth and number of snow days in the eastern and central Tibetan Plateau, Clim. Res., 46, 171-183, 2011.
Zhang, T.: Influence of the seasonal snow cover on the ground thermal regime: An overview, Rev. Geophys., 43, 1-23, 2005. 